Bojan

Žnidaršič

VITRA

Cerknica

\title{
PODEŽELJE POTREBUJE AKTIVNE DRŽAVLJANE
}

\section{Revitalizacija podeželja in koncept aktivnega državljanstva}

$\mathrm{N}_{\mathrm{c}}$ ljanstvo neki? Država nas potrebuje samo za plačevanje davkov, dohodnine, DDV in sem ter tja kakšne kazni. Raje kot aktivne ima pridne in ne preveč zagnane državljane. Sicer pa smo dovolj daleč od oblasti, da nam da mir. Bogu damo, kar je božjega, državi, kar je državnega, drugo pa nas ne briga. Kar se greste vi s to civilno družbo, je tako ali tako nekaj, kar ni niti za na kruh namazati. Torej nepotrebno in nekoristno. Mi vemo, kako je treba stvari urejati brez papirjev, izobraževanja, politike in pametnih ljudi. Zavihamo rokave in naredimo.

Taki in podobni odgovori so kar privreli iz naključnih sogovornikov. Anketni pristop

Prebivalci podeželja so izredno odklonilni do koncepta aftivnega državljanstva. Ali ga sploh razumejo? čutenja, videnja in dojemanja aktivnega državljanstva prebivalcev podeželja je dal za pripravo prispevka kljub hladni prhi - zelo dobra izhodišča. Apatičnost do vsega, kar je povezano $\mathrm{z}$ državo - v političnem žargonu bi temu rekli konstruktivna nezaupnica -, je očitno že postala sestavina naše miselnosti. Zaradi odklonilnega stališča državljanov do aktivnega sodelovanja z lastno državo je postala problematika še bolj zanimiva za obravnavo. Posebej zato, ker je aktivnost osnovni del in temeljni pogoj revitalizacije podeželja.

\section{IMAMO TAKŠNO DRŽAVO, KAKRŠNO SI ZASLUŽIMO}

Prebijanje v srž aktivnega državljanstva začnimo kar z analizo obeh ključnih pojmov. Aktivnost je $\mathrm{v}$ naravnem in socialnem okolju osnova in gonilna sila razvoja, ki je pripeljala človeštvo do današnje stopnje. Razvoj je gibalo vsega (kultura, znanost ...), kar zajema pojem človeštvo. Iz tega lahko potegnemo aksiom, da ni živega bitja na zemeljski obli, ki lahko eksistira brez aktivnosti. Razvoj gre naprej in $\mathrm{v}$ prispevku se ne ukvarjamo z njegovo kakovostjo, ki je vedno diskutabilna. Pojem državljanstvo utrdi besedno zvezo in jo umesti v socialno-ekonomsko-prostorski okvir. Ljudje imamo tako ali drugače državo, ali natančneje, smo prebivalci take ali drugačne države. Znani izrek »Imamo tako državo, kakršno si zaslužimo « spodbuja državljane za aktivno vključevanje v delovanje države. Država je imaginarni pojem, zato bomo v nadaljevanju skušali poiskati tiste vzgibe, ki spodbudijo neaktivne državljane. Razumljivo pa je, da je aktivnost $\mathrm{v}$ tesni povezavi s stopnjo demokratizacije družbe.

$\mathrm{Z}$ napisanimi in nenapisanimi pravili igre smo vsi državljani del zelo zapletenega socialno-gospodarsko-prostorsko-upravnega sistema, imenovanega država. S svojo strukturo upravljanja in predpisovanja pravil igre 
Pogled na razvoj aktivnega državljanstva lahko opredelimo kot dvopolni proces. Prvi pol sega v čase nastajanja držav $z$ združevanjem drużin in plemen, katerega konèni rezultat je bila drźava (zveza držav). Namen države je bil predusem nadvladati šblejšse, individualne razllke so se pogosteje poenotile s prisilo kot konsenzom. Razlika med državami in njhovini ureditvami je bila odvisna od stopnje demokracije. Po konstituiranju države in prebolevanju sotroskkih boleznix se je začel nasprotni proces. Država je uvedla zakonsko regulativo, tako da v okviru pristojnosti ureja in skrbi za svoje državliane. Danes smo v obdobju, ko skušata oba pola bol ali manj uspešno razviti konstruktivni dialog. Povećana individualizacija slabi moć države in krepi moé civilne družbe. Aktivno državljanstvo ustvarjamo vsi prebivalci, povsod in vedno.

določa srednjo, za vse sprejemljivo pot. In kje ima mesto državljan, kajti le on je lahko (samo)aktiven? Aktivnost lahko izraža sam, uspešneje pa $\mathrm{v}$ različnih socialnih, interesnih, zaposlitvenih, izobraževalnih ali celo do države destruktivnih krogih. V tem primeru govorimo o interesnem združevanju, ki ga spodbuja tudi praksa. Organizirana skupina je bolj verodostojen sogovornik državi, za doseganje želenih ciljev je potrebna manjša hrabrost in izpostavljenost posameznika. V dialogu z državo je posameznik praviloma še vedno $v$ podrejenem položaju, zato jo skuša ukaniti. Pravila so zato, da se kršijo, si pravimo, kadar kljub omejitvi hitrosti v naselju prehitro vozimo.

Država je seveda namenjena vsem prebivalcem. Ker pa - hvala bogu - nismo uniformirani, imamo različne poglede in se različno odzivamo na procese, dogodke ... Če nam ne uspe, da bi se utirili na predpisani poti, postanemo deviantni prebivalci. Takrat začutimo vso moč državne prisile. Pojavi se, kadar država (ljudje na položajih, ki to omogočajo) ne sliši zahtev ljudstva. Predstavljajmo si poročen par: "glava družine« na primer nekaj počne ali dela, partner pa je nezainteresiran, če mu že ne nasprotuje. Dane so osnovne okoliščine za neuspešnost take zveze. Zveza med državo in državljani je ravno tak primer, pri katerem (ne)uspešnost omogočajo »konektorji «。 To so aktivni državljani, praviloma združeni v različne nevladne organizacije.

\section{KAJ POMENI AKTIVNO DRŽAVLJANSTVO?}

Aktivno državljanstvo pomeni preseči individualne potrebe posameznika po osnovnih življenjskih potrebah, torej prizadevanje za nekaj več. Aktivni državljani nimajo veliko prijateljev. Vsi jih sicer trepljajo po rami, hvalijo njihovo bistrost in pogum, ko pa potrebujejo njihovo podporo, nastane gluha tišina. Aktiven državljan je lobist in idealist. Razlika med njima je le ta, da se prvi ukvarja s tem strokovno v interesu drugih, drugi pa praviloma manj strokovno, za svoje ideale ali prepričanje. Izkušnje o različnih merilih razdelitve javnih financ $v$ javnih razpisih to (žal še vedno) potrjujejo. Netransparentnost, nedostopnost in zapiranje informacij ter skrivanje ministrstev $\mathrm{z}$ izgovorom na varstvo osebnih podatkov so samo del državne njive, ki potrebuje aktivne orače. Osnova za demokracijo je pravna država, ki ji je (ne)upoštevanje Zakona o javnih naročilih bolj v posmeh kot podporo.

Želja vseh delodajalcev - zaposleni naj bi odgovorno opravljali delo in naj ne bi hodili samo v službo - bi bila lahko bistvo aktivne- 
Po opisanem razmúllanju je aktivno drżavljanstvo vse, kar je kakorkoli povezano z javnim interesom. Praviloma je vedino povezano tudi z javnimi financami. Trenutmo stanje v Sloveniî je s tega stališča slabo, saj sta oportunizem in inertnost (poćakajmo, saj jim tako ali tako ne bo uspelo) moénejša kor prizadevanje za javno dobro. Praksa porrjuje, da imata lobiranje in strankarska pripadnost prevelik pomen v primerjavi s strokovnostjo. Stopnja aktivnega državljanstva je sorazmernas stopnjo denokracije. Je njen kazalnik in pogoj, da smo lahko aktivni brez strahu pred represijo. Aktivno drżavljanstvo ni samo pravica, je predvsem dolżnost reagirati. Pri tem pa je vselej potrebna doloćena stopnja drznosti. Nihèe namré ne mara opozarjanja na napake ali zagovarjanja drugačnh stalisè (razen v parlamentu, lier je to sestavni del robreda $<$ ).

ga državljanstva. Reagirati na vsebine javnega interesa, s katerimi lahko kot posamezni$\mathrm{ki}$ (civilna pobuda) pripomoremo $\mathrm{k}$ izboljšanju, ne da samo mirno in vdani v usodo plačujemo davke. Za dvig samozavesti si lahko postavimo vprašanje, kdo je $\mathrm{v}$ službi koga. Državljan v službi države ali država v službi državljana? Ne glede na težavno komuniciranje $\mathrm{z}$ državo moramo posamezniki jasno in glasno izraziti svoje potrebe, tudi nestrinjanje, če je treba. To nam omogočajo odprt medijski prostor in različne oblike dialoga. EU pripisuje civilni družbi in njenim pobudam velik pomen. Iz izkušenj pa lahko potrdimo primere, ko želijo državne institucije vključiti posameznike in organizirane skupine. Žal prav odziv slovenskih nevladnih organizacij največkrat ni v skladu s pričakovanji. Brez konstruktivnega dialoga in konfrontacije mnenj ni napredka po meri ljudi.

Vrednote družbe in posameznikov so tisti spodbujevalci, ki vplivajo na aktivno državljanstvo. Zato imajo različne oblike izobraževanja izjemno pomembno vlogo pri spodbujanju. Deloma s seznanjanjem o tehničnih možnostih »biti aktiven državljan « (kje, kako, institucije, administrativne poti, zakonodaja ...), še bolj pa v vsebinskem pogledu. Usposobiti ljudi, da začnejo misliti s svojo glavo, je gotovo najpomembnejši cilj aktiviranja prebivalcev. To velja še posebej za tradicionalno pasivno podeželsko okolje.

\section{REVITALIZACIJA PODEŽELJA IN AKTIVNO DRŽAVLJANSTVO}

Ker je kolokvij problematiko aktivnega državljanstva umestil $\mathrm{v}$ izobraževanje odraslih, je smiselno opisati nekatere dileme in praktične rešitve, ki jih uporabljamo v VITRI. Leta 1995 smo zasnovali dolgoročni razvojni revitalizacijski proces (projekt) Dežela suhe robe. Vanj smo vključili hribovite predele 15 občin na Notranjskem in Dolenjskem. Pri našem delu izhajamo iz trenutnih razmer, možnosti in priložnosti regije $\mathrm{v}$ stagnaciji. Zaraščanje kulturne krajine, nekonkurenčna kmetijska proizvodnja, visoka povprečna starostna struktura in upadanje števila prebivalcev so problemi, iz katerih projekt izhaja. Slovenija namenja območju brez ekonomske in politične teže premalo pozornosti. Revitalizacija mora izhajati iz prednosti podeželjskega okolja in vključiti vse prebivalce. Pri tem je izobraževanje odraslih gotovo najpomembnejše sredstvo za uresničitev zastavljenih ciljev. Te lahko dosežemo le z njihovo aktivno vključitvijo. Žal tudi tu velja, da animacija zahteva (pre)več energije.

$\mathrm{V}$ VITRI in aktivni prebivalci s svojim vrednostnim sistemom ocenjujemo, kaj je dobro ali slabo, sprejemljivo ali nesprejemljivo. Vrednote so tista nematerialna kategorija, ki združuje $\mathrm{v}$ sinergetski učinek posameznike s podobnimi nazori. Iz vrednot izhaja tudi vizija »idealnega podeželja «, ki naj bi bilo rezultat naših idej, prizadevanj, pobud, akcij, projektov, predvsem pa konkretnega dela. S ponovno socializacijo podeželja in vaških skupnosti želimo povezati in aktivirati domačine za ekonomski razvoj na osnovah naravne in kulturne dediščine. Naše poslanstvo 
so celovito urejanje domačij, vasi in odprte krajine, razvijanje družinskih podjetij, biokmetijstva in ekoturizma, spodbujanje samozaposlovanja, interesno združevanja domačinov, učenje ročnih spretnosti, trženje suhe robe, oblikovanje, ustvarjalnost, učinkovita raba energije in povečanje deleža obnovljivih virov energije. Nove komunikacijske tehnologije omogočajo prebivalcem podeželja enakopravno sodelovanje na svetovnem trgu. Pogoj za vstop je znanje, temeljni pogoj pa aktivni državljani. Zmožnosti in možnosti prebivalcev je treba materializirati s permanentnim učenjem in aktivnim sodelovanjem. V VITRI smo zaposleni od samega začetka na prvo mesto postavili učenje (formalno in neformalno izobraževanje, informiranje). Sedaj ga prenašamo naprej na različne ciljne javnosti na podeželju.

$\mathrm{V}$ revitalizacijo podeželja vključujemo šte-

Proces aktivnega državllanstva je večplasten. Iz razliénih virov, na različnih ravneh in z različnimi metodami se pridobivajo znanje, izkušnje ... Cilj procesa je usposoblien in motiviran posameznik, ki ima precei znanja ter obvlada take in drugačne vešcine. Pri opredelitvi razlićnih izrazov (vzgoja, izobraževanje in učenje) poudarimo predvsem signifikantne razlike. Vzgoja je najsirssí in najmani konkreten okvir. V njen se zrealita demokracija, pluralnost, spodbujata se individualnost in praviea biti drugaceen. lzobraževanje je ožji okvir, v katerem smo posameznlki vlalučceni v formalne in neformalne oblike izobraževanja. Sprejemamo znanja in stalisca drugh, pri tem oblikujemo svoja stališća in svoj sistem vrednot. Oboje je osnova za nadgradnjo, ki jo z učenjem (azkušnje, samoučenje, razprave, konflikti) lahko doseže le posaneznik. To je najboli konkretna (izvedbena) oblika aktivnega državljanstva.

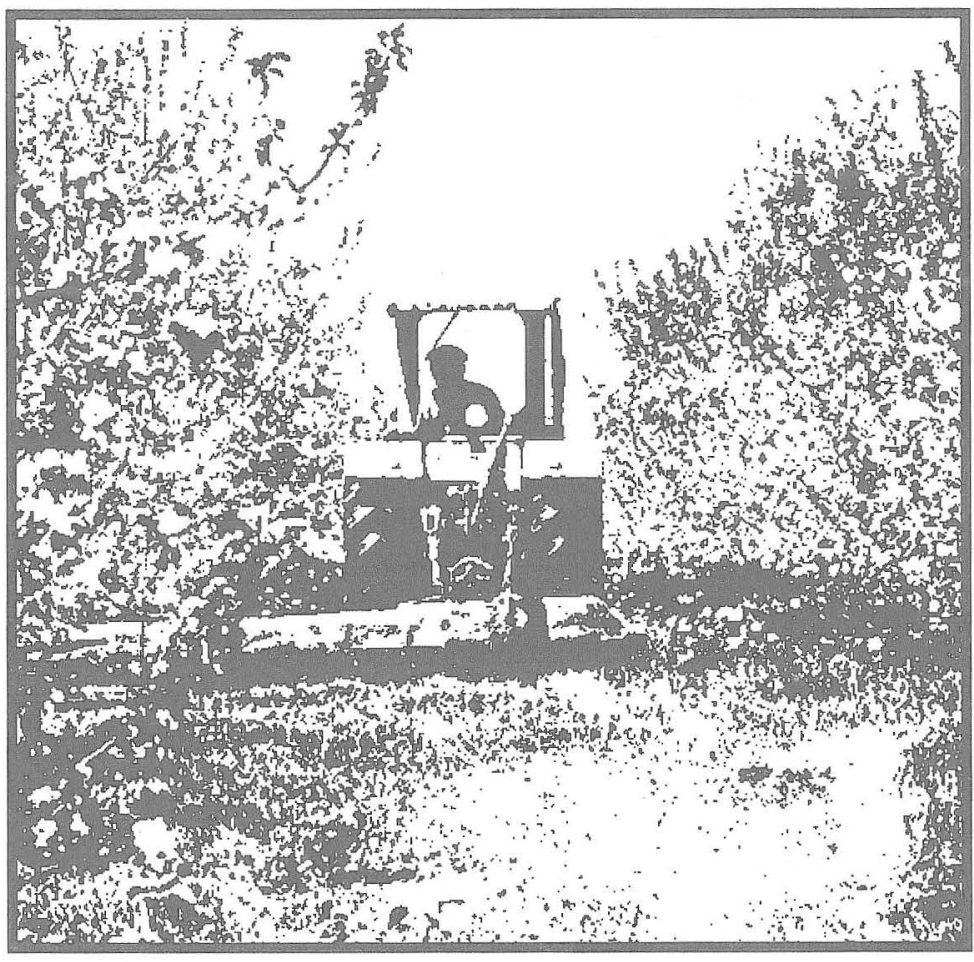

vilne - bolj ali manj aktivne - posameznike in institucije. Kolikor ljudi, toliko okusov, kolikor različnih strok, toliko različnih oblik pojmovanja in razumevanja aktivnega državljanstva. Vsem, ki se trudimo pisano paleto priložnosti revitalizacije podeželja preliti v življenje, so aktivni državljani predvsem aktivni sogovorniki. Tisti, ki vidijo v razvojnih programih priložnost in so pripravljeni tudi aktivno sodelovati. Od zasnove projekta (naloge, aktivnosti) prek vseh izvedbenih faz do rednega delovanja. Aktivno državljanstvo zahteva odgovorno in »odraslo« osebo, ki je pripravljena prevzeti odgovornost za posledice svojih dejanj.

Posameznik je tisti, ki $\mathrm{v}$ javnosti načenja različne, družbeno bolj ali manj pomembne teme. Težko si predstavljamo posameznika s certifikatom aktivnega državljana. Zagotovo pa je do njega upravičen tisti, ki kljub zobobolu vpraša zobozdravnika, zakaj zamuja debelo uro, potem pa se prepusti njegovim rokam in svedrom.
AS 


\section{KAKŠNA ZNANJA POTREBUJE AKTIVEN DRŽAVLJAN?}

Po naših izkušnjah in prepričanju lahko potrebna znanja aktivnega državljana razdelimo $\mathrm{v}$ dva sklopa. $\mathrm{V}$ prvem so tehnična znanja, pridobljena $\mathrm{z}$ državljansko vzgojo, pri kateri se posameznik nauči osnovnih pravil demokracije, delovanja države, pristojnosti posameznih ustanov in institucij, iskanja virov ... Rezultat je tehnično (postopkovno) izobražen in informiran posameznik, ki pozna abecedo in s tem mehanizme delovanja države. Tako kot se v avto šoli naučimo prometnih predpisov in pravil vožnje. Zato je izobraževanje dobra osnova za prvi cilj. Izobraževanje za aktivno državljanstvo spodbudi uporabo pridobljenega znanja $\mathrm{v}$ praksi. Brez osnovnega znanja, pridobljenega z državljansko vzgojo, je izvajanje aktivnega državljanstva težavno in manj uspešno. Kot nam znanje prometnih predpisov še ne zagotavlja obvladanja vožnje avtomobila, tako nam tudi tehnično znanje aktivnega državljanstva ne zagotavlja aktivnih državljanov. Je pa dobra osnova ali celo pogoj. Ker so znanja, potrebna za resno aktivno državljanstvo, manj oprijemljiva, smo jih uvrstili v drugi in najpomembnejši sklop. Cilj je obvladanje vožnje $\mathrm{z}$ avtomobilom in normalno vključevanje $\mathrm{v}$ promet. $\mathrm{V}$ avto šoli je to lažje, pri aktivnem državljanstvu pa cilji niso tako jasni. Tudi interesi in vzgibi posameznikov so zelo različni. Gotovo pa so potrebni samozavest, komunikacijske veščine, analitično razmišljanje, strukturiranost misli, sposobnost pisnega in verbalnega izražanja, razgledanost, splošna izobraženost, strokovno znanje ...

Družba se razmeroma hitro spreminja. $Z$ novimi komunikacijskimi tehnologijami globalna vas vpliva bolj, kot se mogoče zavedamo. Večna dilema izobraževalcev: več splošnega ali več konkretnega se glede aktivnega državljana nagiba na stran splošnega. Informacijska družba temelji na podmeni,
Alivino državljanstvo je vescina, in ne danost, zato zahteva predvsen aktivno razmíllenje. Tega je vse manj, saj namesto nas čedalje boli s razmisljajo nedij, strokovnjaki in poliniki. Cili vsakega izobraževanja je usposobiti posameznika ki je za to zainteresiran - za uspešno delovanje v druzbi.

da so vse informacije že zapisane, treba jih je le poiskati. Ne gre več za nalaganje, kopičenje, produciranje, temveč za izbiranje. Žal tega aksioma ne upoštevata niti formalno niti neformalno izobraževanje kot ena izmed osnovnih obveznosti države. Po definiciji in logiki želi država ideologizacijo izobraževalnih programov in učenje "zaželenih znanj «. Vpletanje dnevne politike v izobraževanje - kot izrazito dolgoročni proces lahko povzroči nacionalno škodo. Zato je dobro, da Slovenija podpira tudi neformalne oblike izobraževanja. Predvsem slednje (ŠK, predavanja, delavnice, seminarji) lahko obravnavajo take vsebine, ki sicer niso zajete $\mathrm{v}$ formalnih oblikah izobraževanja.

Po logiki je izobraževanje vedno $\mathrm{v}$ interesu posameznika, zlasti pa neformalno. Lahko pa gre za nespodbudne okoliščine izobraževanja (čas, lokacija, denar, predhodno znanje, osebne in zaposlitvene potrebe ...). Družba mora omogočiti izobraževanje, posameznik pa se odloči, ali se bo vanj vključil. Samo izobraževanje še ne zagotavlja aktivnih državljanov, je pa večja verjetnost, da bodo to postali. Splošno izobraževanje odraslih je dovolj širok pojem, da ga lahko umestimo tudi v izobraževanje za aktivno državljanstvo. Znotraj tega pa imajo nekatere vsebine gotovo večji pomen. Po našem prepričanju oblika še ne zagotavlja vsebine. Barvanje svilenih rut v krožku še ni aktivno državljanstvo. Vendar je tak krožek dobra osnova, saj spodbuja in omogoča delo v demokratični skupini. 